\title{
Treatment of mucocele of the lower lip using diode laser in a pediatric patient: interdisciplinary case report
}

\author{
Akanksha Raj, Damodar Hegde, Deveshi Gupta, Sangeeta U. Nayak \\ Manipal College of Dental Sciences, Mangalore, India
}

\begin{abstract}
Mucocele or mucus extravasation cyst is a common oral cavity lesion, involving minor salivary glands, and results from duct rupture or obliteration, causing glandular contents (mucinous) to be released subepithelially. The incidence is high, with 2.5 lesions per 1,000 individuals. Indeed, mucoceles are the most common minor salivary gland disorder, and represent the second most frequent benign soft tissue tumors of the oral cavity, following irritative fibromas. Trauma, parafunctional behavior, lip chewing, and other etiological factors may contribute to a permanent bump in the region of incidence if left untreated. These are non-neoplastic cystic lesions of the major and minor salivary glands caused by mucus accumulation. Children are the most often affected by these lesions. Various treatment modalities for mucocele have been advocated, with lasers being the most recent and innovative. In the current case report, a diode laser was used to remove a mucocele on the lower lip, with benefits of less pain, bleeding, recurrence, and greater patient compliance. While these lesions are usually treated with local surgical excision, in our case, to prevent intra-operative surgical complications, such as bleeding and edema, and to facilitate faster healing, excision was performed using a diode laser with a wavelength of $940 \mathrm{~nm}$. After achieving hemostasis, the excised tissue was sent for histopathological examination, which confirmed our diagnosis of that lesion as mucus extravasation cyst or mucocele.
\end{abstract}

HIV AIDS Rev 2021; 20, 4: 314-317

DOI: https://doi.org/10.5114/hivar.2021.111903

Key words: mucocele, lasers, cyst.

\section{Introduction}

In the oral cavity, 'mucocele' refers to an accumulation of mucus secreted by salivary glands and their ducts in subepithelial tissue. Mucoceles, or oral cavity pseudocysts, are the most common minor salivary gland condition and, after irritation fibromas, the second most prevalent benign soft-tissue tumor [1]. They are painless, unless ulcerated as a result of trauma, and appear to recur after treatment, especially when non-surgical methods, such as cryosurgery, intra-lesional corticosteroid injection, or micro-marsupialization are used [1-3]. These lesions are usually described as

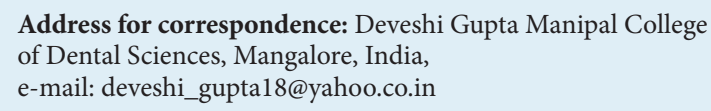

e-mail: deveshi_gupta18@yahoo.co.in

mucoceles, but mucoceles on the side of the mouth floor adjacent to sublingual glands are referred to as 'ranula'. Mucoceles affects people of all ages and genders [1-4]. The asymptomatic nature of mucoceles, which causes patients to not always seek care, may explain the peak incidence between the ages of 10 and 29. Mucoceles can evolve in less than a week or as long as five years, but the most common time period is three weeks to three months. Mucoceles may develop due to repetitive lip or cheek biting or sucking, twitches, or tooth decay. They can also be caused by unintentional damage or pain from orthodontic devices. Extravasation

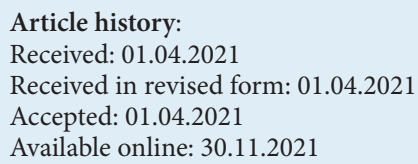


of saliva and mucus from one or more small salivary glands pools in the adjacent submucosal tissue, becomes preserved or walled off, and induces occasional swelling $[4,5]$.

Mucocele may be lined by epithelium or covered by granulation tissue, depending on the type. Lesions are elevated, with no indurations, a flaccid appearance, and thin epithelium. They are red to bluish in color, bluer when localized superficially due to the capillary network visible through them, and reddish when traumatized or situated deeply in tissues [6-8].

Extravasation mucoceles are most prevalent on the labial mucosa, where trauma is most common (45-70\%), but they may also occur on the buccal mucosa, tongue, floor of the mouth, and retromolar area $[1-3,11,12]$. Mucus leaked onto connective tissue from a ruptured or traumatized salivary gland duct is preserved in these mucoceles, which are coated with granulation tissue rather than epithelial tissue $[2,9]$. They account for more than $80 \%$ of all mucoceles, and are most common in patients aged 30 and younger [2]. Extravasation mucoceles lack an epithelial cyst

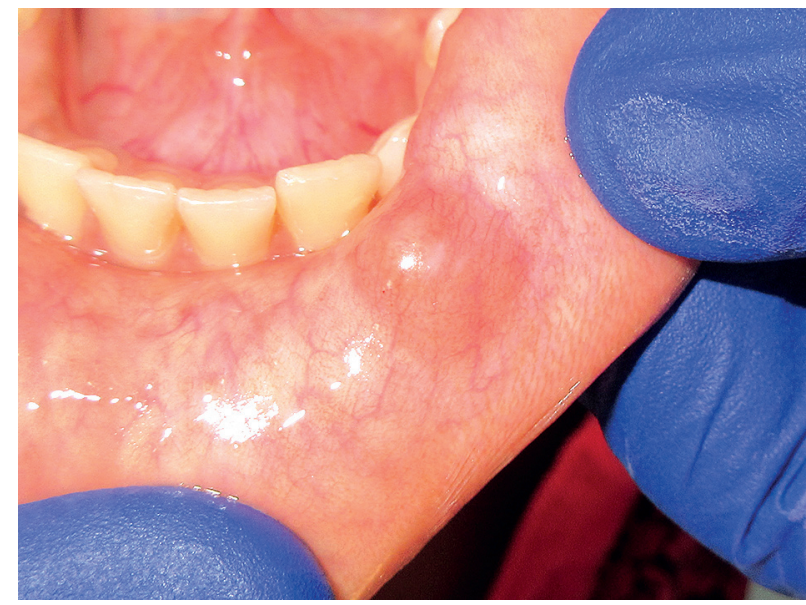

Figure 1. Pre-operative view

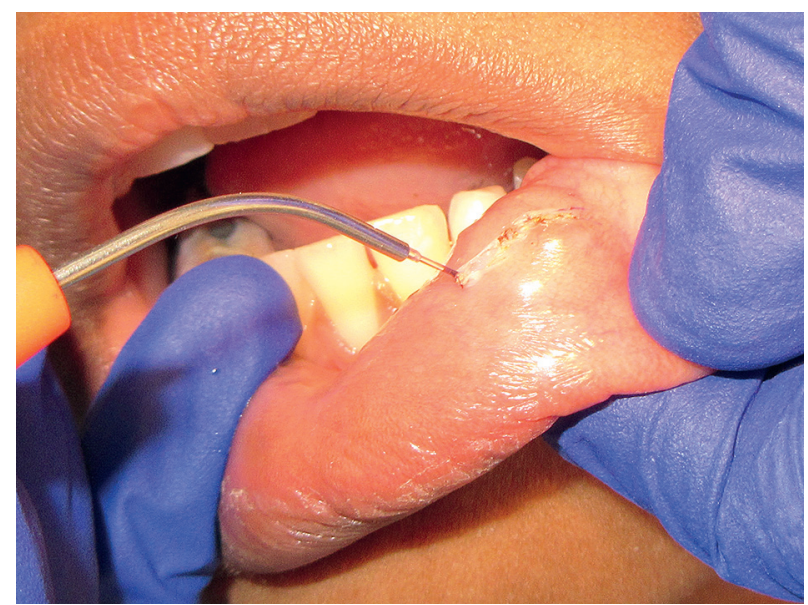

Figure 3. Incision given using diode laser wall and a distinct border, and are composed of adjacent connective tissue and inflammatory components [9-11].

\section{Case description}

A 10-year-old male patient presented with painless swelling on the inner aspect of the lower lip since 3 weeks (Figure 1). Swelling was small initially and then was increasing gradually to attain the present size. There was no significant medical history. Patient had a positive history of lip biting. There was no difficulty in speaking or chewing. On clinical examination, lesion was round, solitary, soft in consistency, painless, fluid-filled, and approximately $1 \mathrm{~cm} \times$ $0.5 \mathrm{~cm} \times 3 \mathrm{~cm}$ in size. The lesion was diagnosed as mucocele based on the clinical appearance and history of lip biting. Various treatment modalities, such as surgical excision, cauterization, and laser excision were explained to the patient's guardian, where guardian opted for treatment using laser. Informed consent letter was duly signed by the guardian before starting of procedure.

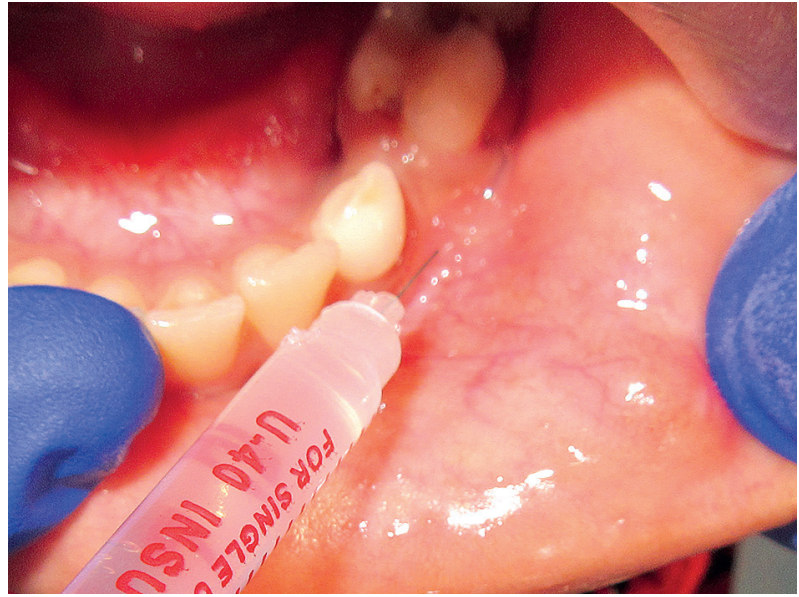

Figure 2. Local anesthesia administered

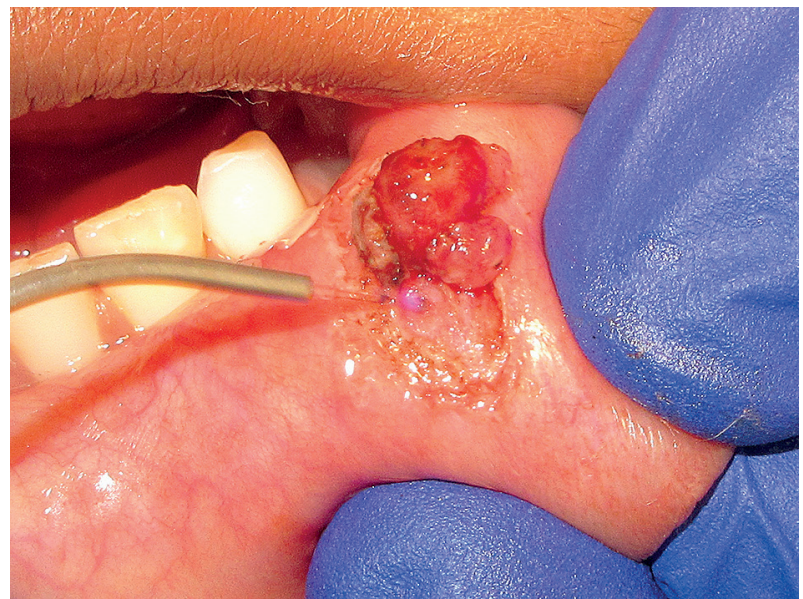

Figure 4. Excision of lesion 


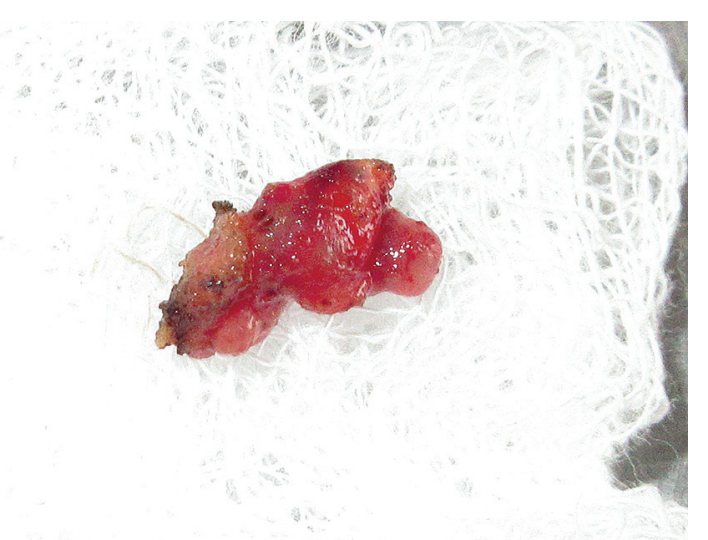

Figure 5. Excised lesion

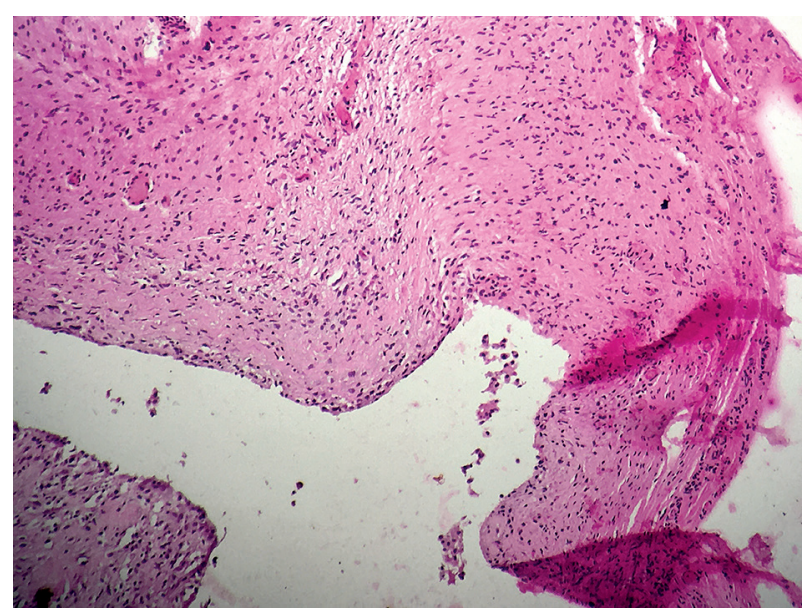

Figure 7. Photomicrograph showing H\&E view cystic cavity lined by thick fibrous capsule, with cystic lumen contains of mucin, foamy macrophages, and chronic inflammatory cells

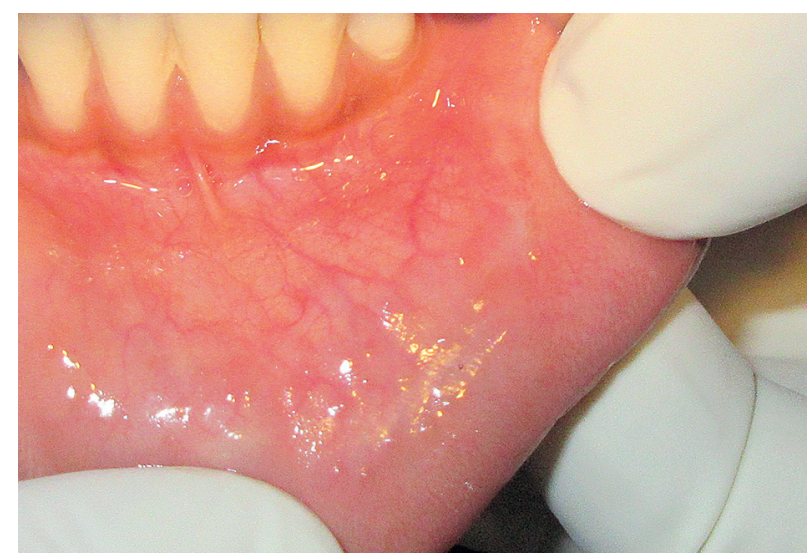

Figure 8. Post-operative view: after 3 weeks

Following minimal infiltration of 2 percent lignocaine with adrenaline $1: 100,000$ (Figure 2), the lesion was excised using soft diode laser in wavelength of $940 \mathrm{~nm}, 300 \mathrm{VA}$,

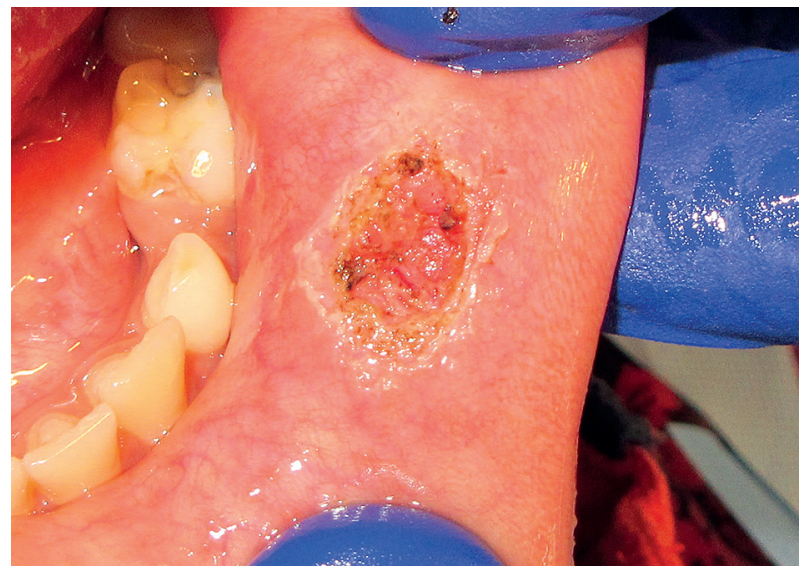

Figure 6. Post-operative view: immediately after procedure

$4.2 \mathrm{~W}$ in continuous mode (Figure 3 ). For safety of the operator, patient, and assistant, all measures were taken. The incision was done on the uppermost site of the lesion and complete excision was performed (Figures 4 and 5). The whole procedure was painless without bleeding, and intra-operative time was reduced; therefore, sutures were no longer needed (Figure 6). The specimen was then subjected to histopathological examination, which showed cystic lumen lined by condensed connective tissue stroma. The cystic lumen indicated presence of muciphages, and connective tissue capsule showed presence of numerous engorged blood vessels, chronic inflammatory cell infiltrate, with predominance of lymphocytes and macrophages (Figure 7). With all these histopathological features, diagnosis of mucous extravasation cyst was given. The patient was prescribed analgesics. There was uneventful healing on 21 days of follow-up (Figure 8).

\section{Discussion}

Mucocele is the second most common oral cavity lesion, followed by irritational fibroma. This lesion is more common in people aged 10 to 29 years old, with an even gender distribution. Mucoceles are dome-shaped mucosal swellings characterized by mucin aggregation. These lesions usually have a bluish, translucent hue, and vary in size from 1-2 mm to several centimeters. The lower lip is the most common site of mucocele occurrence, followed by the buccal mucosa and the floor of the mouth. External swelling, interference with mastication, swallowing, and speech as well as discomfort can occur depending on the size and position of mucoceles [7]. Mucocele histopathology often shows the development of a well-circumscribed, cyst-like space surrounded by granulation tissue as well as the presence of muciphages in the collapsed wall of granulation tissue [10]. Since mucocele should always be removed along with feeder glands/ducts to prevent recurrence of the lesion, the adjacent salivary gland tissue should not be present.

For the early management of mucocele, numerous treatment options are available, including scalpel incision, full surgical excision, marsupialization, micro-marsupialization, 
intra-lesional injections of corticosteroids, cryosurgery, laser ablation, sclerosing agent, and electrocautery methods. Key benefits of soft tissue laser applications are minimal intraoperative bleeding, swelling, and post-operative discomfort as well as very little surgical time, scarring, and coagulation, with no need for suturing after excision due to natural wound dressing caused by denatured proteins. Soft tissue lasers can be used to conduct procedures, including minor and major soft tissue surgery, bone cutting, and implant exposure, with bone removal in patients with bleeding disorders [11, 12].

Semiconductor diode lasers are available in a variety of wavelengths, including $810-830 \mathrm{~nm}, 940 \mathrm{~nm}$, and $980 \mathrm{~nm}$ [13]. The current case was conducted using $940 \mathrm{~nm}$, which has a high affinity for pigments, such as hemoglobin, and can achieve excellent hemostasis [14].

Diode lasers can be a good alternative for larger surgical lasers, such as Er:YAG and $\mathrm{CO}_{2}$ lasers. Their small size and low-cost are the major benefits. They can have a sharp cutting edge as well as coagulation and hemostasis during excisions $[13,14]$.

The absorption of laser energy into the target tissue generates heat through a photothermal mechanism, resulting in intra- and extra-cellular vaporization of cells, cellular explosion, and tissue ablation. Adjacent lateral tissues can also absorb heat if the laser is applied for an extended period of time. This takes place in concentric serial circles around a homogeneous target tissue [14-16]. Thermal effects of laser cause reversible or permanent harm to areas surrounding the target tissue, resulting in zone of coagulation necrosis. Increased time of laser application may result in delayed healing and a larger wound site. However, sealing of small diameter vessels rather than the area of coagulation necrosis offers advantages, such as hemostasis during laser surgery. The area of neighboring coagulation results in less bleeding at the surgical site [15]. The presence of necrotic and coagulated tissue borders in an incisional or excisional biopsy can complicate histopathological identification. Histological analysis of laserextracted tissue reveals increased epithelization and decreased inflammation. There is also an intact basement membrane and connective tissue matrix. Matrix proteins stimulate repair synthesis in these tissues. Reduced scarring and contraction are caused by matrix protein resistance to laser application and replacement as well as removal of residual matrix $[15,16]$.

\section{Conclusions}

In 4 weeks of periodic follow-up, our case report reveals information about using diode laser for the treatment of mucocele with a range of beneficial effects, such as minimal anesthesia, shorter procedure times, good surgical site visualization, hemostasis, and minimal carbonization. It is possible to reduce apprehension and fear in pediatric and geriatric patients using laser technology.

\section{Conflict of interest}

The authors declare no conflict of interest.

\section{References}

1. Qafmolla A, Bardhoshi M, Gutknecht N, Bardhoshi E. Evaluation of early and long term results of the treatment of mucocele of the lip using $980 \mathrm{~nm}$ diode laser. Eur Sci J 2014; 10. DOi: https://doi. org/10.19044/esj.2014.v10n6p\%p.

2. Ellis GL, Auclair PL, Gnepp DR. Surgical Pathology of the Salivary Glands. Philadelphia: Saunders; 1991.

3. Neville BW, Damm DD, Allen M, Bouqot JE (eds.). Oral and Maxillofacial Pathology. $2^{\text {nd }}$ ed. Philadelphia: Saunders; 2002.

4. Madan N, Rathnam A. Excision of mucocele: a surgical case report. Biol Biomed Rep 2012; 2: 115-118.

5. Ata-Ali J, Carrillo C, Bonet C, Balaguer J, Peñarrocha Diago M, Peñarrocha M. Oral mucocele: review of the literature. J Clin Exp Dent 2010; 2: e18-e21.

6. Shear M, Speight P. Cyst of the Oral and Maxillofacial Region. $4^{\text {th }}$ ed. New York: Blackwell Munksgaard; 2007.

7. Re Cecconi D, Achilli A, Tarozzi M, et al. Mucoceles of the oral cavity: a large case series (1994-2008) and a literature review. Medicina Oral, Patologia Oral y Cirugia Bucal 2010; 15: e551-e556. DOI: 10.4317/medoral.15.e551.

8. Yagüe-García J, España-Tost AJ, Berini-Aytés L, Gay-Escoda C. Treatment of oral mucocele-scalpel versus CO2 laser. Medicina Oral, Patologia Oral y Cirugia Bucal 2009; 14: e469-e474.

9. Chawla K, Lamba AK, Faraz F, Tandon S, Arora S, Gupta M. Treatment of lower lip mucocele with Er, Cr: YSGG laser - a case report. J Oral Laser Applications 2010; 10: 181-185.

10. Lee E, Cho SH, Park CJ. Clinical and immunohistochemical characteristics of mucoceles. Ann Dermatol 2009; 21: 345-351.

11. Walsh LJ. The current status of laser applications in dentistry. Australian Dental Journal 2003; 48: 146-155.

12. Azma E, Safavi N. Diode laser application in soft tissue oral surgery. J Lasers Med Sci 2013; 4: 206-211.

13. Robert AC. Principles and Practice of Laser Dentistry. Maryland Heights: Mosby Elsevier; 2010.

14. Agarwal G, Mehra A, Agarwal A. Laser vaporization of extravasation type of mucocele of the lower lip with 940-nm diode laser. Indian J Dent Res 2013; 24: 278.

15. Catone GA, Ailing CC, Smith BM. Laser applications in oral and maxillofacial surgery. Implant Dent 1997; 6: 238. doi: 10.1097/ 00008505-199700630-00026.

16. Luomanen M, Meurman JH, Lehto VP. Extracellular matrix in healing CO2 laser incision wound. J Oral Pathol Med 1987; 16: 322-331. 